\title{
Practicing the Fundamentals of Patient-Centered Care
}

\author{
Muriel Jean-Jacques, MD, MAPP and Matthew K. Wynia, MD, MPH ${ }^{2}$ \\ ${ }^{1}$ Northwestern University Feinberg School of Medicine, Chicago, IL, USA; ${ }^{2}$ Institute for Ethics, American Medical Association, Chicago, IL, USA.
}

J Gen Intern Med 27(4):398-400

DOI: $10.1007 / \mathrm{s} 11606-012-1998-4$

(c) Society of General Internal Medicine 2012

I $\mathrm{n}$ recent debates on resident duty hour regulations, attention has been focused primarily on determining the total amount of time residents should spend on patient care and educational activities. But leaders in graduate medical education have long noted the need to fundamentally restructure the content, not just the quantity, of residents' work days. ${ }^{1-3}$ In particular, major proposals for graduate medical education redesign have sought to ensure that residents' workloads and tasks are better aligned with the aim of developing highly skilled, capable, and compassionate physicians. On the ground, however, most changes to residents' workloads - even those changes that might free up time for focused educational activities, such as the redistribution of various administrative and clinical activities from residents to mid-level practitioners, care managers, and other care team members - have been driven by the need to maintain high volume patient throughput in the face of work hour reforms, rather than reflecting a critical reassessment of what residents should be doing throughout the day to optimize their professional development.

Onto this backdrop, the redesigned inpatient ward team evaluated by Ratanawongsa and colleagues in this issue of $J G I M$ is a bold departure from the traditional model of inpatient resident training. ${ }^{4}$ The key components of the ward team redesign were (1) a patient-centered care curriculum; (2) a more engaged and structured role for attending physicians providing direct supervision and feedback to residents in the areas of patient communication and care coordination; and (3) a substantial reduction in the patient load to about half the usual census.

By many measures, the redesigned team was a success. Compared to the usual ward teams, the intervention team was rated more highly by residents in post-rotation evaluations in improving their ability to know their patients as people, address patient adherence, and communicate with patients. In addition, patient satisfaction surveys revealed that patients discharged from the intervention team had higher ratings of their physicians compared to patients

Published online February 11, 2012 discharged from the usual ward teams. The obvious question, however, is whether the benefits of this type of a patient-centered care focused rotation-particularly one that involves such a significant reduction in the usual team census - are worth the apparent costs, both in terms of the resources needed to make up for lower per-resident productivity and the time potentially diverted from other key training goals. To help answer this, let us consider the main lessons to be learned from this work.

\section{PRACTICE MAKES PERFECT}

First, this study demonstrates that residents and patients benefit from focused, targeted, and supervised practice of patient-centered communication skills. While the value of structured and deliberate practice has been recognized for some procedural aspects of medical care, ${ }^{5-8}$ few training programs have reported using specific rotations that offer focused time and attention to the deliberate practice of more cognitive and interpersonal aspects of medical care, ${ }^{9-11}$ and none of these have focused specifically on the skills needed to deliver patient-centered care. Professional athletes, musicians, and other performers know that they build certain important skills by performing in high-pressure situations (such as the ability to not choke under pressure), but their performance also benefits from focused practice and repetitive exercise of fundamental skills and techniques outside the high-pressure arena. It is incongruous that the value of practicing the fundamentals is so widely preached outside of medicine, yet we expect even novice clinicians to learn almost exclusively from working in high pressure situations.

\section{YOU GET WHAT YOU TRAIN FOR}

The second important contribution of this study to our understanding of inpatient resident training is that a decreased patient load was likely a necessary but not a sufficient contributor to the efficacy of the intervention. Residents on the intervention team received focused and evidence-based training regarding how to assess and understand those social aspects of patients' lives that often affect their medical care (including completion of home visits and post-discharge follow up calls), how to assess and 
address patients' concerns and barriers to adherence to treatment regimens, and how to communicate more effectively with patients and other care providers regarding care transitions - all with enhanced supervision and feedback by attendings who were considered to be experts (either by reputation or by completion of focused training) in these areas. Thus, it is not surprising that the intervention team was ranked more highly by residents and patients in the targeted areas.

Given the substantially reduced patient load, however, some might be surprised that residents did not report improvements in other aspects of resident training that were not explicitly targeted by the curriculum, such as knowledge base, clinical reasoning ability, teaching skills, and physical examination skills. Yet other studies have also found that improvements in resident performance are primarily limited to domains that are explicitly targeted for additional attention. O'Connor and colleagues evaluated an inpatient ward team with reduced patient loads and a focus on improving care team continuity; they found that residents spent more time in direct patient care, but actually less time teaching medical students. ${ }^{10}$ McMahon and colleagues evaluated teams with substantially reduced patient loads and a focus on increased teaching at the bedside; they found improvements in physical examination skills and time spent at the bedside, but no change in patient satisfaction. ${ }^{9}$ In sum, focused practice leads to improvements mainly in the areas that are targeted for practice.

\section{SKILLS TRAINING IN COMMUNICATION IS HELPFUL}

Patient-centered communication has been repeatedly associated with a variety of improved outcomes, ${ }^{12,13}$ but Ratanawongsa and colleagues also add to our understanding that one's ability to communicate effectively with patients is not determined solely by innate personality or temperament. Rather, effective patient-centered communication requires a set of discrete skills that can be acquired with training and refined through practice. ${ }^{14}$ Specifically, patient-centered communication involves the exercise of specific skills to build trusting and therapeutic relationships with patients, elicit and address patients' values and concerns, and exchange information with patients in ways that allow them to make informed decisions and engage in self-management. ${ }^{15}$ These skills can be taught, and doing so will become increasingly important with the evolution of health care, including its growing technical complexity, reliance on health information technology, and emphasis on patient self management.

In summary, the work of Ratanawongsa and colleagues is not simply a study of the effects of a patient-centered care curriculum, nor is it simply a study of the effects of a reduced patient load. Rather, it is a study of the effects of structured, supervised, and focused practice of skills that are fundamental to the everyday practice of patientcentered care. Despite the important lessons from this study, concerns remain regarding the costs associated with creating lower volume teams to provide focused time to teach and practice these skills. Ratanawongsa and colleagues found that halving the census of one team required 1.75 additional hospitalists and suggested that this cost might be offset by reduced readmission rates or greater patient loyalty to the institution, but these hypotheses will need to be verified. In fact, the effects of the intervention team on a variety of outcomes beyond patients' and residents' self-reported satisfaction will be important to understand to assess its ultimate cost-effectiveness. For instance, future work should determine whether the skills learned during the redesigned inpatient ward team experience were retained and applied during subsequent high volume rotations, which might dramatically improve the long-term cost-effectiveness of this intervention. In addition, effective strategies to support the maintenance of patient-centered communication skills even on busy, highvolume rotations should also be explored. These questions notwithstanding, we may find that the ultimate question is not whether we can afford to give every resident focused time to acquire and practice the fundamentals of patientcentered care, but can we afford not to?

Corresponding Author: Matthew K. Wynia, MD, MPH; Institute for Ethics, American Medical Association, 515 N. State Street, Chicago, IL 60654, USA (e-mail: matthew.wynia@ama-assn.org).

\section{REFERENCES}

1. Ludmerer KM, Johns MM. Reforming graduate medical education. JAMA. 2005;294(9): 1083-1087.

2. Fitzgibbons JP, Bordley DR, Berkowitz LR, Miller BW, Henderson MC. Redesigning residency education in internal medicine: a position paper from the Association of Program Directors in Internal Medicine. Ann Intern Med. 2006; 144(12):920-926.

3. Weinberger SE, Pereira AG, Iobst WF, Mechaber AJ, Bronze MS. Competency-based education and training in internal medicine. Ann Intern Med. 2010;153(11):751-756.

4. Ratanawongsa N, Federowicz MA, Christmas C, et al. Effects of a focused patient-centered care curriculum on the experiences of internal medicine eesidents and their patients. J Gen Intern Med. 2011; doi: 10.1007/s11606-011-1881-8

5. Wayne DB, Butter J, Siddall VJ, et al. Mastery learning of advanced cardiac life support skills by internal medicine residents using simulation technology and deliberate practice. J Gen Intern Med. 2006;21(3):251-256.

6. Lenhard A, Moallem M, Marrie RA, Becker J, Garland A. An intervention to improve procedure education for internal medicine residents. J Gen Intern Med. 2008;23(3):288-293.

7. Wayne DB, Barsuk JH, O'Leary KJ, Fudala MJ, McGaghie wC. Mastery learning of thoracentesis skills by internal medicine residents using simulation technology and deliberate practice. J Hosp Med. 2008;3(1):48-54.

8. Barsuk JH, McGaghie WC, Cohen ER, O'Leary KJ, Wayne DB. Simulation-based mastery learning reduces complications during central venous catheter insertion in a medical intensive care unit. Crit Care Med. 2009;37(10):2697-2701. 
9. McMahon GT, Katz JT, Thorndike ME, Levy BD, Loscalzo J. Evaluation of a redesign initiative in an internal-medicine residency. N Engl J Med. 2010;362(14):1304-1311.

10. O'Connor AB, Lang VJ, Bordley DR. Restructuring an Inpatient Resident Service to Improve Outcomes for Residents, Students, and Patients. Acad Med. 2011.

11. Coit MH, Katz JT, McMahon GT. The effect of workload reduction on the quality of residents' discharge summaries. J Gen Intern Med. 2011;26(1):28-32.

12. Venetis MK, Robinson JD, Turkiewicz KL, Allen M. An evidence base for patient-centered cancer care: a meta-analysis of studies of observed communication between cancer specialists and their patients. Patient Educ Couns. 2009;77(3):379-383.

13. Mead N, Bower P. Patient-centred consultations and outcomes in primary care: a review of the literature. Patient Educ Couns. 2002;48 (1):51-61.

14. Rao JK, Anderson LA, Inui TS, Frankel RM. Communication interventions make a difference in conversations between physicians and patients: a systematic review of the evidence. Med Care. 2007;45(4):340-349.

15. Levinson W, Lesser CS, Epstein RM. Developing physician communication skills for patient-centered care. Health Aff (Millwood). 2010;29 (7):1310-1318. 